\title{
NIDDM as a disease of the innate immune system: association of acute-phase reactants and interleukin-6 with metabolic syndrome $X$
}

\author{
J.C.Pickup ${ }^{1}$, M. B. Mattock ${ }^{1}$, G. D. Chusney ${ }^{1}$, D. Burt ${ }^{2}$ \\ ${ }^{1}$ Division of Chemical Pathology, UMDS, Guy's Hospital, London, UK \\ ${ }^{2}$ Unit for Metabolic Medicine, UMDS, Guy's Hospital, London, UK
}

Summary Non-insulin-dependent diabetes mellitus (NIDDM) is commonly associated with hypertriglyceridaemia, low serum HDL-cholesterol concentrations, hypertension, obesity and accelerated atherosclerosis (metabolic syndrome $\mathrm{X}$ ). Since a similar dyslipidaemia occurs with the acute-phase response, we investigated whether elevated acute-phase/stress reactants (the innate immune system's response to environmental stress) and their major cytokine mediator (interleukin-6, IL-6) are associated with NIDDM and syndrome $X$, and may thus provide a unifying pathophysiological mechanism for these conditions. Two groups of Caucasian subjects with NIDDM were studied. Those with any 4 or 5 features of syndrome $\mathrm{X}(n=19)$ were compared with a group with 0 or 1 feature of syndrome $X(n=25)$ but similar age, sex distribution, diabetes duration, glycaemic control and diabetes treatment. Healthy non-diabetic subjects of comparable age and sex acted as controls. Overnight urinary albumin excretion rate, a risk factor for cardiovascular disease, was also assayed in subjects to assess its relationship to the acute-phase response. Serum sialic acid was confirmed as a marker of the acute-phase response since serum concentrations were significantly related to established acute-phase proteins such as $\alpha-1$ acid glycoprotein $(r=0.82, p<0.0001)$. There was a significant graded increase of serum sialic acid, $\alpha-1$ acid glycoprotein, IL-6 and urinary albumin excretion rate amongst the three groups, with the lowest levels in non-diabetic subjects, intermediate levels in NIDDM patients without syndrome $X$ and highest levels in NIDDM patients with syndrome $X$. C-reactive protein and cortisol levels were also higher in syndrome X-positive compared to -negative patients and serum amyloid A was higher in both diabetic groups than in the control group. We conclude that NIDDM is associated with an elevated acute-phase response, particularly in those with features of syndrome X. Abnormalities of the innate immune system may be a contributor to the hypertriglyceridaemia, low HDL cholesterol, hypertension, glucose intolerance, insulin resistance and accelerated atherosclerosis of NIDDM. Microalbuminuria may be a component of the acutephase response. [Diabetologia (1997) 40: 1286-1292]

Keywords NIDDM, acute-phase response, cytokines, interleukin- 6 , innate immune system, insulin resistance syndrome.
Received: 17 April 1997 and in revised form: 6 June 1997

Corresponding author: Dr. J.Pickup, Division of Chemical Pathology, UMDS, Guy's Hospital, London SE1 9RT, UK Abbreviations: VLDL, Very low density lipoprotein; HDL, high density lipoprotein; PAI-1, plasma activator inhibitor-1; NIDDM, non-insulin-dependent diabetes mellitus; CHD, coronary heart disease; IL-6, interleukin-6; TNF- $\alpha$, tumour necrosis factor- $\alpha$.
Although both pancreatic islet beta-cell dysfunction and resistance to the action of insulin are central abnormalities in non-insulin-dependent diabetes mellitus (NIDDM), in most cases the underlying aetiology is unclear. A number of clinical and biochemical features often occur together in subjects with NIDDM, especially hypertension, obesity (particularly central or abdominal obesity), accelerated atherosclerosis, and a dyslipidaemia characterised by elevated serum total and very low-density lipoprotein (VLDL) 
triglyceride and reduced high-density lipoprotein (HDL) cholesterol concentrations $[1,2]$. This has been called the metabolic 'syndrome $X$ ' [2]. Other abnormalities may also be associated with the syndrome, such as high circulating concentrations of plasminogen activator inhibitor-1 (PAI-1) [3]. A pathological mechanism which helps to explain the link between these factors may aid in understanding the cause or causes of NIDDM and lead to improved management. Insulin resistance has been proposed as one such underlying mechanism $[4,5]$, though its molecular basis is not known.

We are investigating an alternative hypothesis which may link the various features of NIDDM: that NIDDM and syndrome $X$ are partly a manifestation of an ongoing acute-phase response, i. e. a component of the innate immune system's adaptive reaction to threatened homeostasis. This might provide a mechanism for most of the features of syndrome X, and some other biochemical abnormalities which have been noted in NIDDM such as hyperfibrinogenaemia [6], low plasma testosterone levels in men with NIDDM [7], as well as elevated circulating PAI-1 levels [3]. In previous studies [8,9], we found that serum sialic acid concentrations are elevated in NIDDM but not in subjects with uncomplicated insulin-dependent diabetes mellitus of comparable age, sex, diabetes duration and glycaemic control (serum sialic acid is essentially protein-bound and has been proposed as a marker of the overall acute-phase response [10] since many acute-phase proteins such as $\alpha-1$ acid glycoprotein and fibrinogen are sialylated at the terminus of the oligosaccharide chain of the glycoprotein [11]). The serum sialic acid concentration was also a highly significant univariate correlate of coronary heart disease (CHD) in a cross-sectional study of male NIDDM patients [12]. Others have reported that experimental induction of an acute-phase response in animals [13] and illnesses in humans likely to be associated with an acute-phase response, such as malignancy $[14,15]$ and infection [16], are characterised by serum lipid and lipoprotein changes identical to those of NIDDM and syndrome X (high serum VLDL triglyceride, low HDL cholesterol, unchanged LDL cholesterol). Moreover, several plasma proteins elevated in NIDDM, e.g. fibrinogen and PAI-1, are known to be acute-phase proteins $[17,18]$.

To test this hypothesis, we investigated whether markers of the acute-phase or stress response (serum sialic acid, C-reactive protein, serum amyloid A, $\alpha-1$ acid glycoprotein and cortisol) and a major cytokine mediator of the acute-phase response, interleukin- 6 (IL-6), are elevated in a group of NIDDM patients selected for having the features of syndrome $\mathrm{X}$, in comparison with an NIDDM group selected for being syndrome X-negative but matched for age, sex, duration of diabetes and quality of glycaemic control. Healthy non-diabetic subjects of comparable age and sex distribution served as controls. We also measured urinary albumin excretion rate in the subjects, since sub-clinical proteinuria (microalbuminuria) is an established risk factor for CHD in NIDDM [19, 20] and is associated with insulin resistance [21]. We therefore tested whether albumin excretion rate segregates with syndrome $X$ and may also be associated with the acute-phase response.

\section{Patients and methods}

Subjects and study design. NIDDM patients were selected from those taking part in the Lewisham Hospital Survey of NIDDM [22]. This is a prospective study in which all NIDDM patients aged 35-64 years attending a diabetic clinic at least once in 1984 are being examined at 3-4 yearly intervals for CHD status and cardiovascular risk factors. From those attending a follow-up clinic in 1994-1995, we studied the 132 of white European origin and from these selected two groups of diabetic patients. Those with 4 or 5 of the following were considered to have syndrome $\mathrm{X}(n=19)$ : hypertriglyceridaemia (VLDL triglyceride $>1.5 \mathrm{mmol} / \mathrm{l}$ ), low serum HDL cholesterol (<1.1 mmol/l), hypertension (systolic blood pressure $>160$ and/or diastolic pressure $>95 \mathrm{~mm} \mathrm{Hg}$ and/or receiving anti-hypertensive drug treatment), CHD (either electrocardiogram evidence or scoring positive on a cardiovascular questionnaire - see below) and obesity (body mass index $[\mathrm{BMI}]>30 \mathrm{~kg} / \mathrm{m}^{2}$ ). Those with 0 or any 1 of these features were designated as syndrome $X$-negative subjects and 25 were selected as being of similar age, sex distribution, diabetes duration and level of glycaemic control (glycated haemoglobin and plasma glucose) to those who were syndrome X-positive. Those with substantive clinical proteinuria (defined here as a urinary albumin excretion rate $>300 \mu \mathrm{g} /$ min) were excluded. The diabetes treatment of the two NIDDM groups was also similar: $0 \%$ diet alone, $28 \%$ insulin and $72 \%$ oral hypoglycaemic agents for syndrome X-negative subjects, and $5 \%$ diet alone, $32 \%$ insulin and $63 \%$ oral hypoglycaemic agents in syndrome $\mathrm{X}$-positive subjects. Healthy non-diabetic subjects $(n=25)$ of comparable age and sex distribution acted as controls, and were Caucasian volunteers from the staff of Guy's Hospital. The study was reviewed and approved by the institution's ethics committee.

Venous blood was taken from all subjects after an overnight fast and the serum stored at either $4^{\circ} \mathrm{C}$ for no longer than 1 week for lipoprotein analysis, or at $-40^{\circ} \mathrm{C}$ for measurement of other analytes, as detailed below. Subjects also supplied a timed overnight urine sample collected into containers with $0.5 \mathrm{ml} 1 \%$ (weight/volume) sodium merthiolate as preservative; their height and weight were recorded in indoor clothing without shoes, and the BMI calculated as weight $(\mathrm{kg}) / \mathrm{height}$ $(\mathrm{m})^{2}$. For assessment of CHD status, the subjects completed the World Health Organisation cardiovascular questionnaire [23] and were scored positive for angina or previous myocardial infarction. A resting 12-lead electrocardiogram was also performed and analysed by the Minnesota code [23]. CHD was considered present for probable ischaemia (code 1-1, 1-2 and 7-1) and possible ischaemia (1-3, 5-1, 5-2 and 5-3). Arterial blood pressure was measured as the mean of two readings on the right arm taken with the subject in the sitting position, after at least $10 \mathrm{~min}$ rest.

Assays. Serum sialic acid concentration was measured by a coupled enzymatic method (Boehringer Mannheim, Lewes, 
Table 1. Clinical and biochemical features of subjects

\begin{tabular}{llll}
\hline & $\begin{array}{l}\text { NIDDM } \\
\text { Syndrome X-positive }\end{array}$ & $\begin{array}{l}\text { NIDDM } \\
\text { Syndrome X-negative }\end{array}$ & Non-diabetic \\
\hline$n$ & 19 & 25 & 25 \\
Age (years) & $61.9 \pm 6.7$ & $61.7 \pm 8.8$ & $56.9 \pm 7.6$ \\
Sex (M/F) & $9 / 10$ & $15 / 10$ & $21 / 23$ \\
Diabetes duration (years) & $12.6 \pm 4.0$ & $11.9 \pm 4.6$ & - \\
BMI (kg/m ${ }^{2}$ & $32.4 \pm 5.2^{\mathrm{a}}$ & $27.0 \pm 4.5$ & $24.0 \pm 2.5$ \\
Glycated Hb (\%) & $8.9 \pm 2.1$ & $8.6 \pm 1.7$ & $5.2 \pm 0.2$ \\
Glucose (mmol/l) & $12.1 \pm 3.9$ & $9.7 \pm 4.3$ & $4.7 \pm 0.3$ \\
Total triglyceride (mmol/l) & $3.3(1.5-7.9)^{\mathrm{a}}$ & $1.0(0.6-2.7)$ & $1.3(0.6-3.0)$ \\
VLDL triglyceride (mmol/l) & $2.3(0.8-6.2)^{\mathrm{a}}$ & $0.5(0.1-2.2)$ & $0.5(0.1-2.7)$ \\
Total cholesterol (mmol/l) & $6.5 \pm 1.1^{\mathrm{d}}$ & $5.9 \pm 0.9$ & $6.3 \pm 0.7$ \\
LDL cholesterol (mmol/l) & $3.7 \pm 0.8$ & $3.6 \pm 0.8$ & $3.8 \pm 0.7$ \\
HDL cholesterol (mmol/l) & $0.9 \pm 0.2^{\mathrm{a}}$ & $1.4 \pm 0.4$ & $1.6 \pm 0.6$ \\
Apolipoprotein A1 (mg/dl) & $1.11 \pm 0.13^{\mathrm{c}}$ & $1.24 \pm 0.20^{\mathrm{e}}$ & $1.47 \pm 0.30$ \\
Apolipoprotein B (mg/dl) & $1.17 \pm 0.25^{\mathrm{b}}$ & $0.99 \pm 0.17^{\mathrm{f}}$ & $1.12 \pm 0.23$ \\
Hypertensive (\%) & 89 & 36 & 0 \\
CHD (\%) & 100 & 0 & 0 \\
\hline Syndrome X-positive vs & & \\
\hline
\end{tabular}

Syndrome X-positive vs negative: ${ }^{\mathrm{a}} p<0.001 ;{ }^{\mathrm{b}} p<0.01 ;{ }^{\mathrm{c}} p<0.02 ;{ }^{\mathrm{d}} p<0.05$

Syndrome X-negative vs non-diabetic subjects: ${ }^{\mathrm{e}} p<0.01 ;{ }^{\mathrm{f}} p<0.02$

Data are mean $\pm S D$, or median (range) for values with skewed distributions

Sussex, UK), adapted by us for use on microtitre plates [24] (inter-assay coefficient of variation $[\mathrm{CV}]$ of $6 \%$ ). Serum amyloid A was measured by enzyme immunoassay (Biosource; Serotec, Oxford, UK) and had an inter-assay CV of 7.6\%. C-reactive protein was also measured by enzyme immunoassay (Medix Biochemica, IDS, Tyne and Wear, UK), the method adapted by us by using a fourfold reduction in sample dilution, thereby decreasing the detection limit to $0.05 \mathrm{mg} / 1$ (inter-assay $\mathrm{CV}$ $3.4 \%$ at $12 \mathrm{mg} / \mathrm{l}$ and $7.8 \%$ at $1 \mathrm{mg} / \mathrm{l})$. The standard was the First International Standard (85/506) for C-reactive protein (NIBSC, South Mimms, Herts, UK). $\alpha-1$ Acid glycoprotein was measured by immunoturbidometry (Binding Site, Birmingham, UK), using a Cobas-Fara analyser (Roche, Welwyn Garden City, Herts, UK) and had an inter-assay CV of $6 \%$. Cortisol was measured by radioimmunoassay (DPC, Llanberis, Gwynedd, UK) with an inter-assay CV of $5 \%$. IL-6 was measured by enzyme immunoassay (Cytoscreen US, Serotec; minimum detection limit $104 \mathrm{fg} / \mathrm{ml}$, interassay CV $7 \%$ ). Urine albumin concentration was measured by radioimmunoassay (inter-assay CV of $8 \%$ ) [25]. Lipoproteins were separated by ultracentrifugation [26]: VLDL density $<1.006 \mathrm{~g} / \mathrm{ml}$, LDL density 1.006-1.063 and HDL density $>1.063$. Apolipoproteins A1 and $\mathrm{B}$ were measured by immunoturbimetric methods (Immuno, Sevenoaks, Kent, UK) using a Cobas-Bio analyser (interassay CV 6 and $9 \%$, respectively). Total and lipoprotein fraction cholesterol and triglyceride were assayed by enzymatic methods (Boehringer). Plasma glucose was assayed by an automated hexokinase method (Roche) and glycated haemoglobin by electroendosmosis after removal of the labile adduct (Ciba Corning, Halstead, Essex, UK).

Statistical analysis. Statistical differences in variables between the three groups were initially tested using analysis of variance, or the Kruskall Wallis test for skewed data. When significant differences at the $5 \%$ level were detected, comparisons were made between two groups using Student's unpaired $t$-test or the Mann Whitney U test for skewed data. Comparison of the frequency of hypertension in those with and without designated syndrome $\mathrm{X}$ was by the chi-squared test. Correlation between variables was tested using either Pearson's method, or Spearman's test for skewed data.

\section{Results}

Features of NIDDM patients and the control subjects. Table 1 shows the clinical and biochemical characteristics of the three groups studied. NIDDM patients who had the most features of syndrome $\mathrm{X}$ were, by selection, obese and had higher VLDL triglyceride, and lower HDL cholesterol compared to the syndrome X-negative NIDDM subjects. They also had higher serum total triglyceride and lower apolipoprotein A1 levels than the syndrome $X$-negative patients. The LDL-cholesterol concentrations were similar in the diabetic groups and non-diabetic controls. Total serum cholesterol and apolipoprotein B concentrations were slightly but significantly higher in those diabetic subjects with syndrome $\mathrm{X}$ compared to those without syndrome $\mathrm{X}$.

Serum sialic acid as a marker of the acute-phase response. There was a highly significant correlation $(r=0.82, p<0.0001)$ between serum $\alpha-1$ acid glycoprotein and sialic acid concentrations in the whole group of NIDDM subjects. There were also significant correlations between the serum sialic acid concentration and the other acute phase proteins measured, C-reactive protein $(r=0.71, p<0.0001)$ and serum amyloid A $(r=0.56, p<0.001)$, thus confirming that serum sialic acid is a marker of the acutephase response in these groups. The correlation between serum sialic acid and cortisol concentration was, however, less marked $(r=0.27, p=0.07)$.

Acute-phase responses in subjects. Figure $1 \mathrm{a}-\mathrm{d}$ shows the concentrations of the acute-phase markers serum sialic acid, $\alpha-1$ acid glycoprotein, C-reactive protein and serum amyloid $\mathrm{A}$ in the diabetic and control 

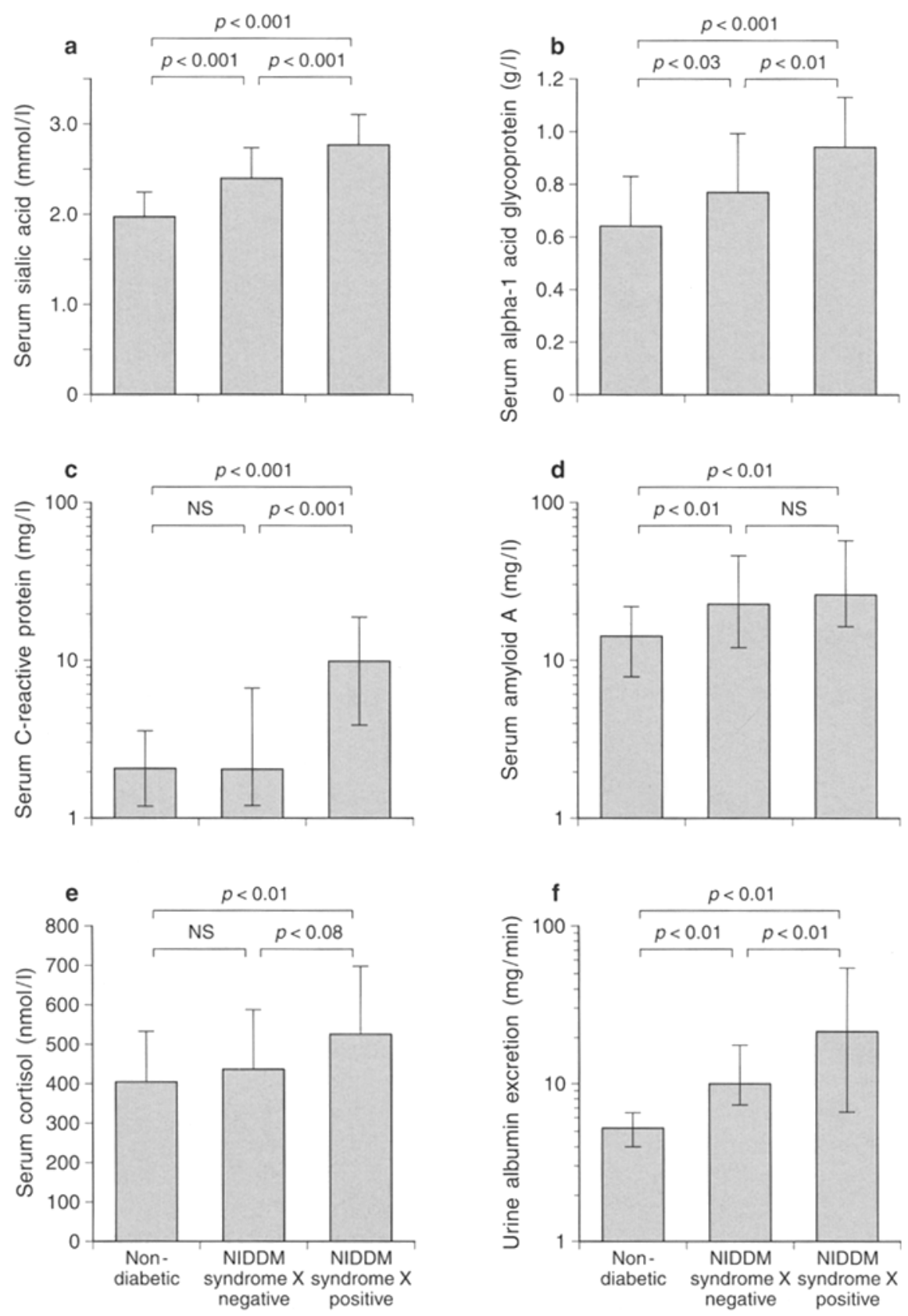

Fig. 1 a-f. Serum sialic acid (a), $\alpha-1$ acid glycoprotein (b), Creactive protein (c), serum amyloid $\mathrm{A}$ (d) and cortisol concentrations (e), and urinary albumin excretion rate (f), in non-diabetic subjects (left column) and NIDDM patients with (right column) and without syndrome $X$ (middle column). Columns are mean $\pm \mathrm{SD}$ except for $\mathrm{C}$-reactive protein, serum amyloid $\mathrm{A}$ and albumin excretion (median \pm interquartile range)

groups. There were clear graded increases in serum sialic acid and $\alpha-1$ acid glycoprotein concentrations, with the lowest levels in non-diabetic persons, intermediate levels in syndrome $\mathrm{X}$-negative NIDDM subjects and highest levels in syndrome X-positive NIDDM subjects. C-reactive protein concentrations were also higher in syndrome $\mathrm{X}$-positive compared to $\mathrm{X}$-negative patients (though similar in the latter

group and controls). Serum amyloid A concentrations, though not differing between diabetic groups, were higher than in the non-diabetic controls.

Figure $1 \mathrm{e}$ shows that serum cortisol concentrations were higher in NIDDM subjects with syndrome X compared to those without these features and non-diabetic control subjects. Urinary albumin excretion rate also showed a graded increase (Fig. 1f) with the highest levels in those NIDDM patients with syndrome $X$, intermediate levels in those without syndrome $\mathrm{X}$ and lowest levels in non-diabetic subjects.

Serum IL-6 concentrations. Figure 2 shows that there was also a highly significant graded increase in serum IL-6 concentrations, with low levels in non-diabetic subjects, intermediate levels in syndrome $\mathrm{X}$-negative 


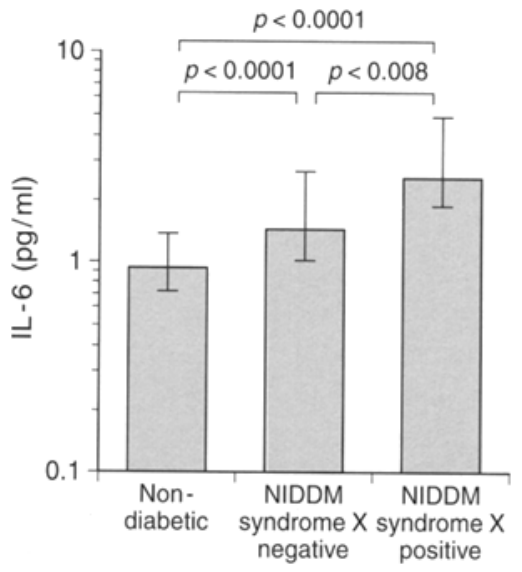

Fig. 2. Serum interleukin-6 concentrations in non-diabetic subjects, and NIDDM patients with and without syndrome $\mathrm{X}$. Columns are median \pm interquartile range

patients and highest levels in syndrome $\mathrm{X}$-positive patients.

\section{Discussion}

This study provides evidence that NIDDM is associated with increased serum levels ofmarkers of, and the major inducer of, the acute-phase response, i.e. the wide range of molecular, cellular, physiological and behavioural changes that are initiated in response to stressful stimuli such as infection, inflammation, neoplasm, and physical and chemical tissue injury $[17,18]$. These changes are adaptive mechanisms designed to restore homeostasis during and after external threats. We found that those patients with NIDDM and the cluster of biochemical and clinical features known as syndrome $X$ had the highest concentrations of most acute-phase markers; those with NIDDM but few features of syndrome $X$ had an intermediate-level acute-phase response, but still higher than non-diabetic control subjects. Increases in circulating acute-phase proteins have been recorded before in diabetes $[27,28]$ but the particular associations with NIDDM and syndrome $X$ have not been noted.

The changes in acute-phase reactants that we found are small compared with those associated with an acute infection, but their impact is of significance because the changes are likely to be chronic. In support of the importance of even low-grade stimulation of the acute-phase response, Feingold et al. [29] found that the dose of endotoxin needed to induce hyperlipidaemia in rats (by stimulating hepatic triglyceride secretion) was orders of magnitude lower than that necessary to induce shock. An augmented acutephase response may thus be one unifying mechanism to explain many of the characteristics of NIDDM. For example, an increased secretion of VLDL, and reduced serum HDL but relatively unchanged LDL cholesterol, the dyslipidaemia of NIDDM and syndrome $X$, are known acute-phase responses in animals [13] and humans [14-16]. The acute-phase protein, serum amyloid $\mathrm{A}$, which we found to be elevated in NIDDM, is an apolipoprotein which associates with $\mathrm{HDL}_{3}$, displacing apolipoprotein $\mathrm{A} 1$ and acting as a signal to redirect HDL cholesterol from the liver to the macrophage for use in repairing injured tissue $[18,30]$. Sustained elevated concentrations of serum amyloid A may thus be a factor in the accelerated atherosclerosis of NIDDM.

We also found that IL-6, which with IL-1 and tumour necrosis factor $\alpha$ (TNF- $\alpha$ ) is one of the main cytokine mediators of augmented hepatic acute-phase protein synthesis [31], is elevated in NIDDM patients, particularly those with syndrome $X$. These cytokines stimulate the release of the diabetogenic hormones growth hormone and ACTH from the anterior pituitary gland, and increase production of hypothalamic corticotrophin-releasing hormone (CRH) [3234]. $\mathrm{CRH}$ is known to inhibit gonadotrophin secretion [35], perhaps accounting for the low testosterone concentrations seen in men with NIDDM [7]. Hypercortisolism, as well as contributing to the insulin resistance, glucose intolerance and hypertension of NIDDM, produces central obesity (for example in Cushing's syndrome), and elevates non-esterified fatty acid concentrations and VLDL secretion. A possible role for glucocorticoid excess as a result of a 'hypothalamic arousal syndrome' in obesity has been discussed by others [36-38], particularly drawing on evidence from animal studies. By showing in this study that acute-phase proteins and IL-6 are increased in NIDDM, we extend this concept to include a possible wide-ranging pathophysiological role for these proteins and their cytokine inducers in NIDDM and its biochemical and clinical complications.

Acute-phase proteins which are known to be increased in NIDDM include fibrinogen [6], complement components [39] and PAI-1 [3]. As well as affecting hepatic protein synthesis, lipoprotein metabolism [40] and the hypothalamic pituitary axis, TNFo, IL-1 and -6 contribute to atherogenesis in several other ways such as by inducing adhesion molecules, stimulating smooth muscle proliferation and increasing endothelial permeability [41]. $\mathrm{TNF} \alpha$, a potent inhibitor of the tyrosine kinase activity of the insulin receptor, is being investigated as a mediator of insulin resistance in obesity and NIDDM [42]. The inhibitory effect of IL-1, IL- 6 and TNF $\alpha$ on pancreatic beta-cell function is recognised in the context of a possible role in the aetiology of islet cell destruction in IDDM [43, 44]; the effect of any chronic hypersecretion of cytokines on insulin secretion in NIDDM has yet to be studied in detail.

Our finding that the urinary albumin excretion rate was highest in syndrome $\mathrm{X}$ patients and segregated 
with the highest acute-phase response, is consistent with the link between microalbuminuria and insulin resistance [21]. The role of the acute-phase response and related cytokines as a mechanism for increasing glomerular capillary permeability therefore needs further investigation.

With regard to the mechanism for the augmented acute-phase response in NIDDM, several possibilities may be envisaged. Firstly, it may be caused by the NIDDM state, though apparently not by hyperglycaemia, since there is no correlation between serum sialic acid concentrations and either glycated haemoglobin or plasma glucose levels [12]. Recently, we showed in animal models of diabetes that insulin deficiency is significantly related to elevated serum sialic acid concentrations [45]; moreover, insulin is an inhibitor of acute-phase protein synthesis in vitro [46, 47]. Insulin resistance may therefore be an inducer of the response, perhaps with hypercortisolaemia providing an additional stimulatory effect on hepatic acute-phase protein synthesis [17].

Secondly, a localised inflammatory response associated with atherosclerosis, with cytokine production by all cells involved in the atherosclerotic plaque [41], may induce a systemic acute-phase response. A 'haematological stress syndrome' in non-diabetic subjects with atherosclerosis was recognised more than a decade ago [48], and recent studies confirm an association between acute-phase indices such as C-reactive protein and sialic acid and CHD in the normal population [49]. In the present study, however, even NIDDM patients without atherosclerosis had greater resting serum levels of acute-phase markers than non-diabetic control subjects, suggesting atherosclerosis exacerbates but does not initiate the acute phase response. With regard to the role of complications, it should be noted also that advanced glycosylation end products stimulate cytokine release from macrophages [50,51] and these could act in concert with insulin deficiency/resistance to induce an acute-phase response in the diabetic patient with tissue complications.

It may be supposed that, in the short term, a prominent stress response with biochemical, hormonal and behavioural alterations to counter injury, has survival value and certain individuals are genetically or innately predisposed to have such a response, for example by metabolic 'programming' during fetal or early life [52]. However, chronic exposure in these subjects to stressful stimuli, such as overnutrition, physical inactivity and age, may produce disease (e.g. NIDDM and atherosclerosis) instead of repair. It is relevant that both the acute-phase response [53] and the production of cytokines from macrophages [54] increase with age, parallelling the association of NIDDM with increasing age.

In conclusion, NIDDM is associated with an augmented, acute-phase response which is particularly marked in, but not confined to, those with syndrome X. The stimulus for this response is unknown, and it is not our contention that NIDDM is caused by this mechanism, that it is the only causative factor in insulin resistance and the other features of the syndrome associated with it, or that it is of relevance in all NIDDM subjects. However, we believe that abnormalities of the innate immune system deserve further investigation as contributors to the pathophysiology of NIDDM and as factors which at least exacerbate its important features, including glucose intolerance, insulin resistance, central obesity, hypertension, accelerated atherosclerosis, hypertriglyceridaemia, hyperfibrinogenaemia, low blood HDL cholesterol, high PAI-1 and low testosterone concentrations in diabetic men.

Acknowledgements. We are most grateful to the BUPA Foundation, the Special Trustees of Guy's Hospital and the Wellcome Trust for financial support.

\section{References}

1. Kaplan NM (1989) The deadly quartet: upper-body obesity, glucose intolerance, hypertriglyceridemia and hypertension. Arch Intern Med 149: 1514-1520

2. Wajchenberg BL, Malerbi DA, Rocha MS, Lerario AC, Santomauro ATMG (1994) Syndrome X: a syndrome of insulin resistance. Diabet Metab Rev 10: 19-29

3. Yudkin J (1995) Coronary heart disease in diábetes mellitus: three new risk factors and a unifying hypothesis. J Intern Med 238: 21-30

4. Reaven GM (1988) Role of insulin resistance in human disease. Diabetes 37: 1595-1607

5. Zavaroni I, Bonora E, Pagliara M et al. (1989) Risk factors for coronary heart disease in healthy persons with hyperinsulinemia and normal glucose tolerance. N Engl J Med 320: $702-760$

6. Ganda OM, Arkin CF (1992) Hyperfibrinogenemia: an important risk factor for vascular complications in diabetes: Diabetes Care 15: 1245-1250

7. Barrett-Connor E (1992) Lower endogenous androgen levels and dyslipidemia in men with non-insulin-dependent diabetes mellitus. Ann Intern Med 117: 807-811

8. Crook M, Tutt P, Pickup JC (1993) Elevated serum sialic acid concentration in non-insulin-dependent diabetes and its relationship to blood pressure and retinopathy. Diabetes Care 16: 57-60

9. Crook MA, Tutt P, Simpson H, Pickup JC (1993) Serum sialic acid and acute phase proteins in type 1 and 2 diabetes mellitus. Clin Chim Acta 219: 131-138

10. Taniuchi K, Chifu K, Hayashi N et al. (1981) A new enzymatic method for the determination of sialic acid in serum and its application as a marker of acute phase reactants. Kobe J Med Sci 27: 91-102

11. Rosenberg A, Schengrund C-L (1976) Circulating sialyl compounds. In: Rosenberg A, Schengrund S (eds) Biological roles of sialic acid. New York, Plenum pp 275-294

12. Pickup JC, Mattock MB, Crook MA, Chusney GD, Burt D, Fitzgerald AP (1995) Serum sialic acid concentration and coronary heart disease in NIDDM. Diabetes Care 18: 1100-1103 
13. Cabana VG, Siegel JN, Sabesin SM (1989) Effects of the acute phase response on the concentration and density distribution of plasma lipids and apolipoproteins. J Lipid Res 30: $39-49$

14. Blackman JD, Cabana VG, Mazzone T (1993) The acutephase response and associated lipoprotein abnormalities accompanying lymphoma. J Intern Med 233: 201-204

15. Spiegel RJ, Schaefer EJ, Magrath IT, Edwards B (1982) Plasma lipid alterations in leukemia and lymphoma. Am J Med 72: 775-782

16. Olsson AG (1991) Non-atherosclerotic disease and lipoproteins. Curr Opin Lipidol 2: 206-210

17. Kushner I, Mackiewicz A (1993) The acute phase response: an overview. In: Mackiewicz A, Kushner I, Baumann $\mathrm{H}$ (eds) Acute phase proteins: molecular biology, biochemistry and clinical applications. CRC Press Boca Raton, pp 3 19

18. Steel DM, Whitehead AS (1994) The major acute phase reactants: C-reactive protein, serum amyloid $\mathrm{P}$ component and serum amyloid $A$. Immunol Today 15: 81-87

19. Jarrett RJ, Viberti GC, Argyropoulos A, Hill RD, Mahmud U, Murrels TJ (1984) Microalbuminuria predicts mortality in non-insulin-dependent diabetes. Diabet Med 1: 17-19

20. Mogensen CE (1984) Microalbuminuria predicts clinical proteinuria and early mortality in maturity-onset diabetes. N Engl J Med 310: 356-360

21. Groop L, Ekstrand A, Forsblom C et al. (1993) Insulin resistance, hypertension and microalbuminuria in patients with type 2 (non-insulin-dependent) diabetes mellitus. Diabetologia 36: 642-647

22. Mattock MB, Keen H, Viberti GC et al. (1988) Coronary heart disease and urinary albumin excretion in type 2 (non-insulin-dependent) diabetic patients. Diabetologia 31: $82-87$

23. Rose G, Blackburn H, Gillum RF, Prineas RJ (1982) Cardiovascular survey methods. WHO Mongr Series 56 pp 162-165

24. Simpson H, Chusney GD, Crook MA, Pickup JC (1993) Serum sialic acid enzymatic assay based on microtitre plates. Br J Biomed Sci 50: 164-167

25. Keen H, Clouverakis C (1963) An immunoassay for urinary albumin at low concentration. Lancet ii: 913-916

26. Havel RJ, Eden HA, Bragdon JH (1955) The distribution and chemical composition of ultracentrifugationally separated lipoproteins in human serum. J Clin Invest 34: 13451353

27. Jonsson A, Wales JK (1976) Blood glycoprotein levels in diabetes mellitus. Diabetologia 12: 245-250

28. McMillan DE (1989) Increased levels of acute-phase serum proteins in diabetes. Metabolism 38: 1042-1046

29. Feingold KR, Staprans I, Memon RA et al. (1992) Endotoxin rapidly induces changes in lipid metabolism that produce hypertriglyceridemia: low doses stimulate hepatic triglyceride production while high doses inhibit clearance. J Lipid Res 33: 1765-1776

30. Kisilevsky R (1991) Serum amyloid A (SAA), a protein without a function: some suggestions with reference to cholesterol metabolism. Med Hypoth 35: 337-341

31. Baumann H, Gauldie J (1994) The acute phase response. Immunol Today 15: 74-80

32. Dinarello CA (1991) Interleukin-1. In: Thomson AW (ed) The cytokine handbook. Academic Press London, pp 47-82

33. Akira S, Taga T, Kishimoto T (1993) Interleukin-6 in biology and medicine. Adv Immunol 54: 1-78

34. Jaattela M (1991) Biological activities and mechanisms of action of tumor necrosis factor $\alpha /$ cachectin. Lab Invest 64 : 724-742
35. Rivier C, Vale W (1984) Influence of corticotrophin-releasing factor on reproductive functions in the rat. Endocrinology 114: 914-921

36. Brindley DN (1992) Neuroendocrine regulation and obesity. Int J Obes 16 [Suppl 3]: 73-79

37. Björntorp P (1992) Biochemistry of obesity in relation to diabetes. In: Alberti KGMM, DeFronzo RA, Keen H, Zimmet P (eds) International textbook of diabetes. John Wiley Chichester pp 551-568

38. Jeanrenaud B (1995) Insulin, corticosterone and the autonomic nervous system in animal obesities: a viewpoint. Diabetologia 38: 998-1002

39. Figueredo A, Ibarra JL, Bagazgoitia J et al. (1993) Plasma C3d levels and ischemic heart disease in type II diabetes. Diabetes Care 16: 445-449

40. Feingold KR, Grunfeld C (1992) Role of cytokines in inducing hyperlipidemia. Diabetes 41: [Suppl 2] 97-101

41. Yokota T, Hansson GK (1995) Immunological mechanisms in atherosclerosis. J Intern Med 238: 479-489

42. Hotamisligil GS, Spiegelman BM (1994) Tumor necrosis factor $\alpha$ : a key component of the obesity-diabetes link. Diabetes 43: 1271-1278

43. Bendtzen K, Buschard K, Diamant M, Horn T, Svenson M (1989) Possible role of IL-1, TNF $\alpha$ and IL-6 in insulin-dependent diabetes mellitus and autoimmune thyroid disease. Lymphokine Res 8: 335-341

44. Rabinovitch A (1994) Immunoregulatory and cytokine imbalances in the pathogenesis of IDDM. Diabetes 43: 613621

45. Pickup JC, Day CD, Bailey C et al. (1995) Plasma sialic acid in animal models of diabetes mellitus: evidence for modulation of sialic acid concentrations by insulin deficiency. Life Sci 57: 1383-1391

46. Thompson D, Harrison SP, Evans SW, Whicher JT (1991) Insulin modulation of acute-phase protein production in a human hepatoma cell line. Cytokine 3: 619-626

47. Campos SP, Baumann H (1992) Insulin is a prominent modulator of the cytokine-stimulated expression of acutephase plasma protein genes. Mol Cell Biol 12: 1789-1797

48. Stuart J, George AJ, Davies AJ, Aukland A, Hurlow RA (1981) Haematological stress syndrome in atherosclerosis. J Clin Pathol 34: 464-467

49. Mendall MA, Patel P, Ballam L, Strachan D, Northfield TC (1996) C-reactive protein and its relation to cardiovascular risk factors: a population based cross sectional study. $\mathrm{Br}$ Med J 312: 1061-1065

50. Vlassara H, Brownlee M, Manogue KR, Dinarello C, Pasagian A (1988) Cachectin/TNF and IL-1 induced by glucose modified proteins: role in normal tissue modelling. Science 240: $1546-1548$

51. Imani F, Horii Y, Suthanthiran M et al. (1993) Advanced glycosylation endproduct-specific receptors on human and rat T-lymphocytes mediate synthesis of interferon $\gamma$ : role in tissue remodelling. J Exp Med 178: 2165-2172

52. Barker DJP, Hales CN, Fall CHD, Osmond C, Phipps K, Clark PMS (1993) Type 2 (non-insulin-dependent) diabetes mellitus, hypertension and hyperlipidaemia (syndrome $\mathrm{X}$ ): relation to reduced fetal growth. Diabetologia 36: 62-67

53. Caswell M, Pike LA, Bull BS, Stuart J (1993) Effect of age on tests of the acute-phase response. Arch Pathol Lab Med 117: 906-910

54. Fagiolo U, Cossarizza A, Scala E et al. (1993) Increased cytokine production in mononuclear cells of healthy elderly people. Eur J Immunol 23: 2375-2378 